\title{
Perancangan Mini Game Bergenre Adventure Mengunakan Aplikasi Game Maker
}

\author{
Nia Oktaviani ${ }^{1)}$ Nurul Adha Oktarini Saputri ${ }^{2)}$ \\ Universitas Bina Darma \\ Jalan Jenderal Ahmad Yani No.12 Palembang \\ nia240486@ gmail.com ${ }^{1)}$ nurul12242009@gmail.com ${ }^{21}$
}

\begin{abstract}
Abstrak
Game merupakan sebuah aplikasi yang hampir semua orang memilikinya. Dalam menggunakan sebuah game kebanyakan orang menggunakan game maker karena lebih mudah dan walaupun tampilannya tidak begitu menarik.Banyak dari kalangan orang awam sampai orang ahli,terlebih lagi orang IT yang hampir setiap hari tidak lepas dari komputer dalam tingkat pemakaian berbagai game yang dimainkan, yaitu salah satunya game maker.Tugas makalah ini bertujuan untuk mengenalkan game maker untuk menghibur,baik anakanak maupun orang dewasa. Manfaat dari game maker itu sendiri untuk menghilangkan rasa stress.

Walaupun memang terkesan tidak bagus tapi ini memang untuk pemula bagi pelajar yang ingin membuat game yang simple dan mudah tersebut. Memang tidak susah tapi memerlukan kreaativitas apabila ingin membuatnya menjadi lebih menarik yang terpenting adalah anda telah memulai bagaimana cara membuat game anda sendiri.Adapun metedologinya dimulai dengan merancang game yang akan dibuat untuk menyesuaikan kebutuhan user yang menggunakanya.Pemasangan game maker ini sendiri sudah disediakan terlebih dahulu dengan menggunakan database.Terakhir kesimpulan dan saran untuk menyesuaikan kebutuhan pengguna yang menggunakan game maker.
\end{abstract}

Keywords-Perancangan, aplikasi, game maker.

\section{PENDAHULUAN}

\section{Latar Belakang}

Dalam beberapa tahun terakhir,permainan elektronik atau yang sering kita dengar dengan sebutan video game yang telah pesat mengalami kemajuan.Games merupakan suatu permainan yang menggunakan media elektronik, dimana game dibuat semenarik mungkin untuk dapat memberikan kepuasan kepada pemain. Diera modern dan perkembangan teknologi sekarang ini, semua kalangan sudah mengenal apa yang disebut dengan game dari anak kecil hingga desawa suka terhadap tekologi yang dihasilkan ini. Tidak terbatas pada kalangan tertentu, hal ini dapat kita lihat pada suatu daerah terpencil hinggadi ibu kota terbesar,banyak sekali game-game unik maupun yang terpopuler sekalipun.Game maker ini sendiri tidak seperti halnya yang ada diwarnet ataupun game online lainnya,game maker ini sendiri mereka memiliki pelanggan tetap yang lebih banyak dari pada game yang ada diwarnet ataupun game online lainnya.Disamping itu,biaya yang dikeluarkan digame maker ini cenderung lebih murah daripada bermain game yang ada diwarnet.Inilah yang membuat game maker hampir selalu ramai dikunjungi mulai dari orang dewasa hingga anakanak.

Game sekarang tidak seperti yang dahulu.Jika dahulu game hanya bisa maksimal dimainkan dua orang ditempat yang sama, sekarang dengan kemajuan teknologi terutama jaringan internet, game bisa dimainkan oleh 100 orang atau lebih dalam waktu yang bersamaan diseluruh dunia. Bahkan ada beberapa game yang telah memakai kartu untuk pembayaran game tersebut

\section{Rumusan Masalah}

Adapun rumusan masalah pada penelitian ini yaitu bagaimana merancang aplikasi mini game yang bergenre adventur dengan menggunakan aplikasi game maker.

\section{PEMBAHASAN}

a. Definisi Game Maker 
Game maker adalah sebuah game engine yang bisa membantu anda membuat sebuah game komputer tanpa menggunakan codingan yang banyak dengan bahasa programan. Dengan game maker anda dapat membuat game 2D, 3D atau multiplayer, dan anda juga mempunyai hak penuh terhadap game yang anda buat.

Game maker memungkinkan untuk membuat permainan dengan menggunakan drag-and-drop sederhana,sehingga tidak perlu memiliki pengalaman coding sebelumnya. Ini mencakup pilihan bahasa pemrograman untuk menambahkan fitur-fitur canggih pada permainantanpa perlu menulis satu baris kode.

Menurut David Parlett, Game adalah sesuatu yang memiliki "akhir dan cara mencapainya": artinya ada tujuan, hasil dan serangkaian peraturan untuk mencapai keduanya.

Menurut Roger Caillois, seorang sosiolog Perancis, dalam bukunya yang berjudul Les jeux et les hommes menyatakan game adalah aktivitas yang mencakup karakteristik berikut: fun(bebas bermain adalah pilihan bukan kewajiban), separate (terpisah), uncertain, non-productive, governed by rules (ada aturan), fictitious (purapura).

\section{b. Sejarah dan perkembangan Game Maker}

GameMaker (awalnya bernama Game Maker dan sering disingkat GM) awalnya dikembangkan oleh Mark Overmars dalam bahasa pemrograman Delphi. Saat ini dikembangkan dan diterbitkan oleh Yoyo Games, sebuah perusahaan perangkat lunak di mana Overmars secara tidak langsung terlibat dan pemegang saham besar GameMaker.

Game Maker awalnya berjudul Animo, dan dimulai sebagai program untuk membuat animasi 2D.Mark Overmars merilis versi publik pertama dari GameMaker (versi 1.1) pada tanggal 15 November 1999.Sementara versi Game Maker memiliki built-in scripting bahasa, yang tidak serumit seperti di versi yang lebih baru, dan beberapa versi berikutnya Game Maker tidak memiliki dukungan DirectX.

Setiap rilis utama mereka menambahkan fitur baru yang besar dan peningkatan stabilitas sambil mendapatkan terus dalam popularitas.Pada tahun 2001, versi 3.0 diimplementasikanDirectX untuk pertama kalinya, sementara versi 4.0 (dirilis Juli 2001) ditulis ulang dari awal, mengubah interface secara signifikan.

\section{c. Kemampuan Grafik}

GameMaker terutama berjalan game yang menggunakan grafis 2D. Kemampuan grafis GameMaker ini mengalami perbaikan yang signifikan dengan setiap versi rilis utama, memungkinkan untuk fungsionalitas tambahan termasuk penyesuaian alpha lebih efisien dan pengaturan pencampuran untuk sprite dan bentuk lainnya.Dengan versi 6.0 (Windows), Game Maker dimasukkan DirectX, yang memungkinkan fungsi-fungsi grafis yang lebih canggih.Versi 7.0 (Mac OS X) menggunakan OpenGL untuk membuat sprites.

Dimulai dengan versi 6.0 (Windows), Game Maker menambahkan Direct3D, yang memungkinkan penggunaan grafis $3 \mathrm{D}$ yang terbatas.Untuk versi 7.0 (Macintosh) dan atas, OpenGL digunakan untuk grafis 3D dan juga memungkinkan dukungan terbatas untuk model 3D yang sederhana.Converter digunakan untuk membuatnya mungkin untuk menggunakan format 3D yang lebih populer seperti $.3 \mathrm{ds}$, dan .obj untuk digunakan dalam proyek 3D.Paket ekstensi seperti Ogre digunakan untuk memperluas fungsi dasar Game Maker ini.

Hal ini juga mendukung kemampuan untuk membuat efek partikel seperti hujan, salju dan awan, namun tidak native dalam 3D kecuali melalui penggunaan Dynamic Link Library.Dukungan untuk mengedit 32-bit .png file ditambahkan dalam versi 8.0 dari perangkat lunak yang juga memungkinkan pengguna untuk menggunakan gambar dengan alpha channel.

\section{d. Bagian - Bagian Game Maker}

Di dalam game maker terdapat baberapa resource yang anda dapat gunakan untuk membuat sebuah Game dalam game maker.

\section{- Sprites:}

Gambar dari semua objek dalam game.

\section{- Sound:}

Efek efek suara agar game terasa lebih hidup.

- Backgrouds:

Gambar yang digunakan untuk latar belakang sebuah game yang sedang berlangsung.

- Paths:

Paths adalah lintasan yang diikuti oleh suatu objek dalam game.

- Scripts:

Bahasa Pemrograman pada GameMaker

- Fonts:

Jenis huruf yang digunakan pada game.

- Time Lines: 
Pemberian waktu pada objek dalam melakukan suatu Action pada game.

- Objects:

Kumpulan beberapa benda benda yang ada pada game.

- Event:

Pergerakan yang dilakukan oleh suatu objek apabila terjadi suatu peristiwa pada objek tersebut.

- Room:

Ruangan dimana game berjalan dan juga sebagai tempat untuk suatu objek untuk di letakan atau tempat suatu objek untuk bergerak.

\section{e. Kelebihan Pada Game Maker}

- $\quad$ Mudah digunakan karena adanya fasilitas Drag and Drop.

- Tidak terlalu perlu menggunakan Bahasa Pemrograman.

- $\quad$ Lengkap dengan program pendukung.

- Dapat membuat jenis game apa saja.

\section{f. Jenis Game Maker}

\section{a) Game Maker 8}

Game maker 8 adalah sebuah aplikasi yang biasa digunakan untuk membuat game berbasis 2D dan 3D tapi sayangnya game maker 8 hanya terfokus pada game yang dibuat 2D dari pada 3D ,tapi anda tidak bisa membuat game sekelas dengan Eart of empire II, pada aplikasi ini! karena ketersediaan alat pada game maker 8 sangat terbatas, sehingga para pembuat game biasanya membuat game 2 dimensi,untuk bisa membuat game yang bisa digunakan untuk membuat game 3Dimensi ini antara lain:

- 3D game studio

- 3 Ds $\max 7$

- dan masih banyak lagi

\section{b) Game Maze}

Game Maze merupakan jenis game yang membutuhkan ketangkasan kita dalam menentukan jalan yang tepat untuk menyelesaikan suatu level, game jenis ini memang sederhana, namun bisa cukup adikitif, jika kita mampu meramunya dengan lebih kreatif, dan menambahkan berbagai elemen pendukung didalam game ini.

Dan sampai sekarang pun, maze tetap digunakan pada game game modern, lihat saja berbagai dungeon yang ada diberbagai game rpg, atau maze maze remuit nan megah di berbagai game platform $3 \mathrm{~d}$ yang sering kita temui saat ini.Game Maze memang menjadi ciri khas, dan memiliki tantangan tersendiri dan akan selalu digunakan diberbagai jenis genre game dikemudian harinya

\section{Perancangan Game}

\section{Gambaran umum}

Game ini merupakan permainan yang menceritakan tentang petualangan dalam sebuah labirin dalam mendapatkan koin, kunci dan bendera untuk melanjutkan ke level berikutnya. Adapun dalam perjalanannya itu terdapat berbagai

rintangan atau musuh yang mengganggunya. Sehingga harus menghindari dari musuh-musuh tersebut, karena apabila gagal akan mengulangi permainan. Berikut rincian game yang akan dibuat :

1. Game bergenre Adventure.

2. Sistem permainan singleplayer.

3. Game terdiri dari 4 level permainan.

4. Tokoh yang ada dalam game ini adalah satu karakter utama dan empat karakter musuh.

\section{Analisa Kebutuhan Fungsional}

- Use Case Diagram

Dengan diagram use case dapat diperoleh gambaran mengenai kebutuhan sistem yang akan digunakan dan juga memberi gambaran tentang fungsi yang dikehendaki pada saat sistem dijalankan. Diagram use case dapat dilihat pada Gambar berikut:

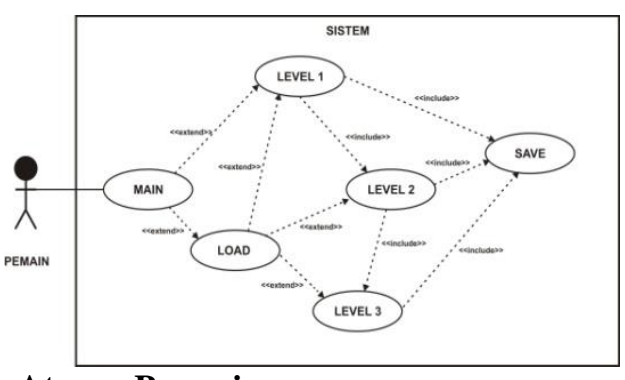

Aturan Permainan

Ada beberapa aturan dasar dalam permainan ini:

- Dipermainan ini anda akandisuruh untuk menghabiskan makanan agar bisa Finish dan lanjut ke level selanjutnya.

- Pemain dapat memakan musuh apabila dia mendapatkan icon bonus. 
- Pemain mengendalikan aktor dari musuh yang mendekatinya ataupun yang akan dilewatinya.

- Pada awal permainan aktor memiliki 3nyawa.

- Tombol yang harus digunakan

Up : : untuk arah keatas

Down : untuk arah bawah

Right : untuk arah kanan

Left : untuk arah kiri

Esc : untuk End game

\section{Media Input}

Media input adalah alat untuk memainkan atau mengkomunikasikan antara permainan dengan pemain, sehingga pemain bisa dengan mudah menggunakannya.

\section{Rancangan Level Game}

Perancangan level game sangat berpengaruh bagi pemain. Perancangan level game ini berisi mengenai bermacam segment yang dipakai serta berapa tingkat kesulitan masing-masing level yang di buat pada perancangan game dan juga game play yang bertahap

\section{g. Langkah-langkah Membuat Game Maker Untuk Pengguna Sebagai Pembelajaran Nilai Positif}

Pertama, Download Games Maker versi gratis di internet kemudian instal di PC anda softwareini cukup mudah untuk digunakan bagi para pemula.Fiturnya yang simple dan mudah dipahami sehingga sangat cocok untuk para pelajar dalam memahaminya.

Software ini juga bisa didownload secara gratis di berbagai blog maupun situs game yang ada. Jadi, tidaklah sulit untuk mencarinya. Dengan membuat game sendiri dapat menambah nilai positif pada kegiatannya diluar sekolah.

$$
\begin{aligned}
& \text { O Pertama buka aplikasi Game } \\
& \text { Maker }
\end{aligned}
$$

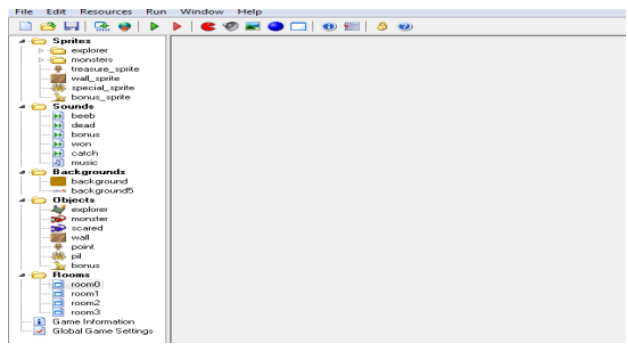

○ Lalu kita buat Sprite nya

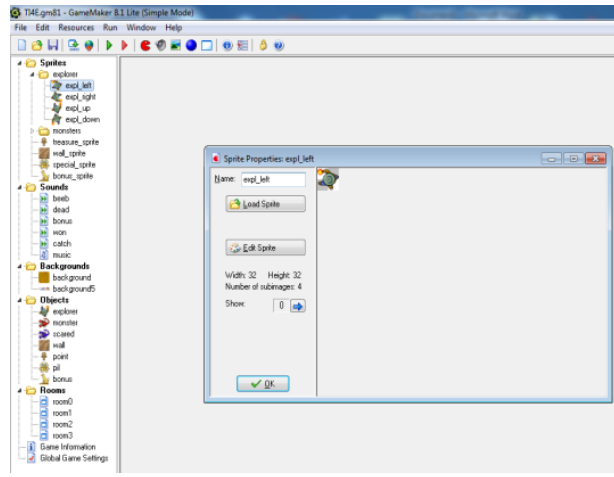

- Membuat Sound untuk sprite-sprite yang telah dibuat

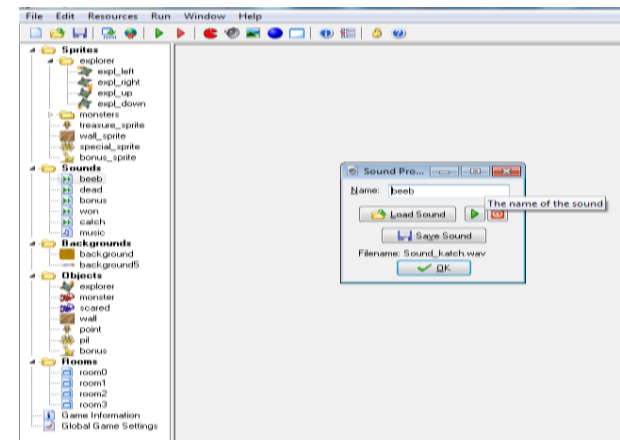

- Membuat Background yang telah disiapkan oleh aplikasi itu sendiri

(seperti gambar di bawah ini)

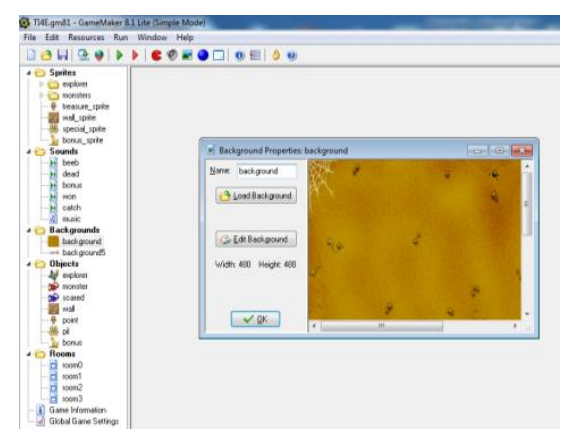

- Memasukkan sprite ke dalam objek yang ingin kita buat serta menambahkan action sesuai keinginan kita. 


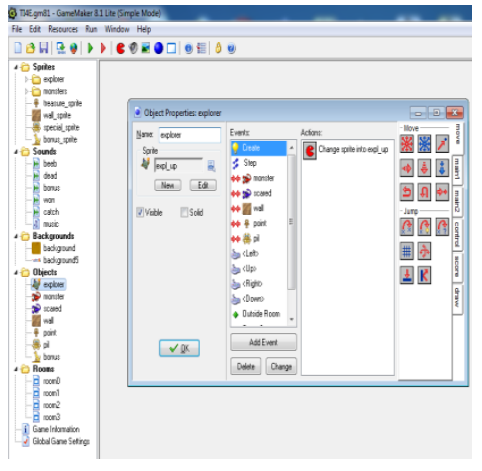

○ Membuat room agar seluruh sprite,sound,object,background dikumpulkan menjadi satu dan menjadi lah sebuah game mini yang berjenis adventure

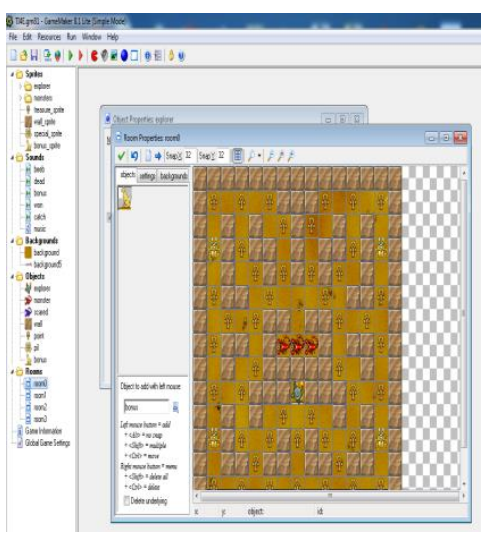

○ Klik Play untuk melihat game yang telah dibuat tadi. Coba gunakan tombol arah pada keyboard anda, Maka game tersebut dapat dilihat

(seperti gambar dibawah ini)

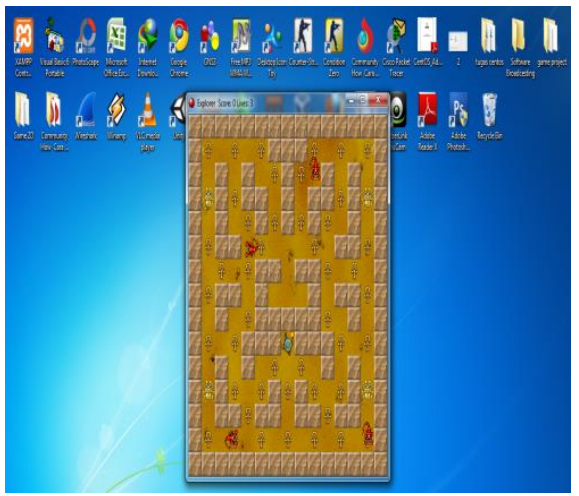

○ Dan jadilah sebuah mini games Adventure yang dapat dimainkan kapan saja

\section{PENUTUP}

\section{A. Kesimpulan}

Game Meker sangat berguna bagi masyarakat, karena game ini sangat bermanfaat untuk membantu daya ingat anak/membuat anak cerdas dari game yang dimainkan. Game ini juga memang mempunyai banyak manfaat bagi masyarakat untuk menunjang daya pikirnya. Namun bila dalam pemakaian tidak dikontrol dapat mengakibatkan kebiasaan dan menimbulkan manfaat buruk nantinya. Maka dari itu perlu diingat dan dianjurkan bagi semua kalangan baik anak-anak maupun pelajar agar jangan terlalu sering untuk memainkan game,agar tidak menimbulkan dampak negative dari game tersebut.

\section{B. Saran}

Berdasarkan pembahasan masalah yang ada diatas, disarankan bagi pelajar agar :

1) Mengurangi intensitas bermain game

2) Mencari kesibukan lain agar terlepas dari kecanduan bermain game

3) Meningkatkan prestasi akademik

4) Berhati-hatilah dengan radiasi media visual video game, karena bisa mengganggu kerja tubuh dan otak

5) Pintar memilih waktu dan jenis permainan, yang lebih edukatif

\section{DAFTAR PUSTAKA}

[1] http://imyudha.blogspot.com/2013/05/gamemaker.html

[2] http://rasyidhadi.wordpress.com/2012/08/17/pe ngertian-dari-game-maker-8/

[3] http://virtuastudios.blogspot.com/2012/03/mem buat-game-maze-sederhana-dengangame.html

[4] http://jintoples.blogspot.com/2012/03/dasardasar-membuat-game-dengangame.html\#.U6BFwGXKvqQ

[5] http://repository.amikom.ac.id/files/Publikasi_1 0.01.2692,\%2010.01.2697.pdf

[6]http://oliviajuliandae.blogspot.com/2013/0 3/game.html 